\title{
Draft Ratios for Stabilizing Fly Ash from Incineration Plants
}

\author{
Marcela Malindzakova ${ }^{1 *}$, Andrea Rosova1, Dusan Malindzak ${ }^{2}$ \\ ${ }^{1}$ Institute of Logistics, Technical University of Kosice, BERG Faculty, \\ Park Komenskeho 14, 040 00, Kosice, Slovakia \\ ${ }^{2}$ Consultant, U. S. Steel Kosice, Vstupny areal U. S. Steel Kosice, 044 54, Kosice, Slovakia
}

Received: 4 July 2016

Accepted: 18 August 2016

\begin{abstract}
As current trends indicate, the amount of waste materials from production processes and from general consumption is rapidly increasing everywhere. Such wastes include solid, liquid, and gaseous elements representing all industrial sectors as well as different waste types of any kind. On the one hand there is an increasing shortage of certain raw materials, and on the other hand the ever-present danger associated with handling various hazardous wastes. Therefore, one can assume with great certainty that more sophisticated and more effective utilization of wastes will define the future orientation of material and energy management $[1]$.
\end{abstract}

Keywords: incineration process, solidification, fly ash, stabilization, cementation

\section{Introduction}

As the above indicates, it is important to deal with waste, where for the purposes of this article the focus is on fly ash created during the incineration of municipal waste. Currently, there are two basic technological approaches for processing fly ash: the first by solidification and the second by stabilization - each representing different types of physico-chemical waste treatment [2]. Both approaches belong to environmental technologies and can be applied to remove a wide range of hazardous wastes, in both solid and liquid forms. Such treatment is used to achieve the following:

- Reduced mobility and solubility of pollutants.

- Reduced toxicity and ecotoxicity of waste.
- Enabling more secure handling and transportation of waste by improving the physical properties of waste (formation of a solid matrix).

- Reduce waste surface area, thereby reducing the possibility of an environmental leak.

Fly-ash is the unwanted byproduct of the waste incineration process, released during burning and captured by filters. Considering that ash resulting from the waste incineration process classified as hazardous waste according to act No. 129/2004 of the Ministry of Environment of the Slovak Republic, it is necessary to address appropriate methods of handling fly ash. The environmental legislation of the European Union also makes the rules for fly ash export much more restrictive, especially with regard to its export to landfills, increasing also the fees for disposal of this hazardous waste. Organizations are therefore forced to apply appropriate technologies for the treatment of fly ash [3].

*e-mail: marcela.malindzakova@tuke.sk 


\section{Material and Methods}

Solidification/stabilization is a term that covers a range of technologies and processes involving the use of additives and binders to eliminate the extent of contaminated sites (Fig. 1). The priorities of solidification/ stabilization methods for toxic waste involve [4-5]:

- Limiting the portability and solubility of waste.

- Reducing the toxicity of waste and their impact on the environment.

- Changing the physical characteristics of waste and facilitating better handling of hazardous waste.

- Preventing a leak of toxic substances into the environment.

Solidification is the process of physical change and amalgamation of contaminated materials into a single, mechanically resistant material with limited permeability of the structure. This change, however, does not affect the chemical properties. During the process of solidification, conversion occurs to change the powder and liquid waste into a solid form. This creates barriers that reduce the possibility of toxic substances leaking into the environment. The solidification technologies used for this purpose are: cementation, bituminisation, vitrification, and fixation into appropriate materials.

Stabilization is a process in which a chemical bond occurs, binding pollutants into a stable form with highly reduced solubility. This process may not affect the physical properties of the polluted material. The stabilization process aims to transform the pollutants into a chemically and physically stable form in order to isolate the toxic substances from the environment. It is necessary to mix the pollutant material with a binding medium or with other supporting chemical agents (additives). The most commonly used additives are cement, fly ash, and metallurgical slag. Within the stabilization process a number of chemical reactions occur, where the resulting substrate is solidified and much less prone to leakage [6].

In common everyday practice, a company can utilize the cementation process to homogenize the toxic waste with cement at regular temperatures. This type of solidification is used for organic materials such as fly ash from the incineration of municipal waste. The binding

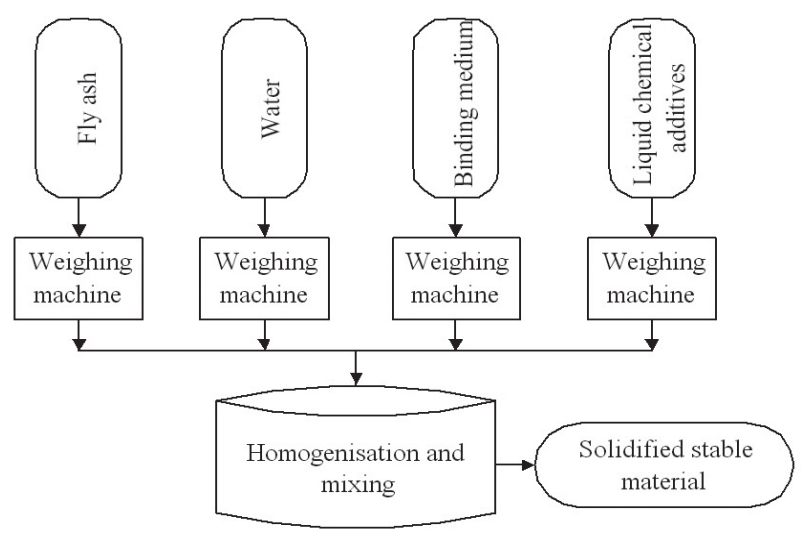

medium used for this purpose includes portland cement, old-portland cement, and quick-binding cement [7].

\section{Results and Discussion}

The main advantage of utilizing cementation is the low cost, and the disadvantage is the relatively large volume of the compacted product. During the research phase it was necessary to determine a suitable mixture composition and to identify the optimal ratio between the fly ash and cement. By identifying a suitable ratio, it was possible to achieve a sufficiently homogenized mixture ad to meet the statutory legislation limits for storage of stabilized pollutants landfill, considering both the convenience and the costs. For that reason several mixture ratios were tested:

1. $5 \%$ cement and $95 \%$ fly ash.

2. $10 \%$ cement and $90 \%$ fly ash.

3. $25 \%$ cement and $75 \%$ fly ash.

4. $90 \%$ cement and $10 \%$ fly ash.

Based on the laboratory analyses results considering the respective rations it was necessary to establish a set of constraints (Eqs 1-4). To establish the said set of constraints a graphic optimization solution was used. The target function is represented by limit for a particular chemical (in Eq. 5).

The main task was to find a suitable mixture ratio of cement and fly ash, to maintain minimal financial costs, and to maintain lower concentrations of chlorides than the limit value of $1,500 \mathrm{mg} \cdot \mathrm{l}^{-1}$. Therefore, it was necessary to calculate the coordinates of lines to determine the optimal graphic solution (Fig. 2). Based on the proportions of fly ash and cement, the coordinate lines are calculated for chlorides. The coordinates in Table 1 define the lines in a standard X-Y system. The intersections of these lines define the polygon area of a graphic optimal solution. The coordinates of polygon apexes for the area of an optimal solution are shown in Table 2.

The following set of constraints presents mixture ratios:

95. $x_{1}+5 . x_{2} \geq$ value of given chemicals from laboratory analysis

90. $x_{1}+10 . x_{2} \geq$ value of given chemicals from laboratory analysis

75. $x_{1}+25 . x_{2} \geq$ value of given chemicals from laboratory analysis

90. $x_{1}+10 . x_{2} \geq$ value of given chemicals from laboratory analysis

Fig. 1. Solidification / stabilization unit. 


\section{Target function: $\mathrm{x}_{1}+\mathrm{x}_{2} \leq$ limit value}

The last mixture ratio is not adequate, considering the effectiveness and the steep financial costs.

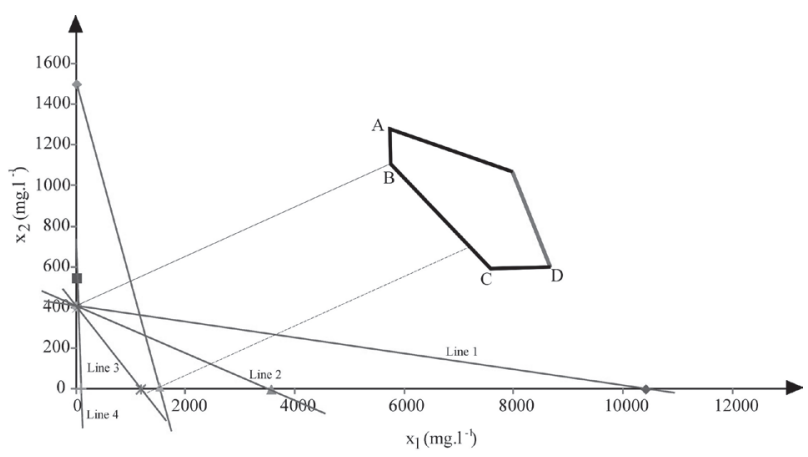

Fig. 2. Graphic solution for chlorides.

Table 1. Coordinates of lines (chlorides).

\begin{tabular}{|c|c|c|}
\hline & $\mathrm{x}_{1}$ & $\mathrm{x}_{2}$ \\
\hline Line 1 & 10,406 & 547 \\
\hline Line 2 & 3,557 & 400 \\
\hline Line 3 & 1,174 & 391 \\
\hline Line 4 & 50 & 453 \\
\hline Limit & 1,500 & 1,500 \\
\hline
\end{tabular}

Table 2. Coordinates of the polygon apexes for chlorides.

\begin{tabular}{|c|c|c|}
\hline & $\mathrm{x}_{1}$ & $\mathrm{x}_{2}$ \\
\hline $\mathrm{A}$ & 7 & 395 \\
\hline $\mathrm{B}$ & 7 & 389 \\
\hline $\mathrm{C}$ & 1,500 & 0 \\
\hline $\mathrm{D}$ & 0 & 453 \\
\hline
\end{tabular}

Table 3. Chloride values.

\begin{tabular}{|c|c|}
\hline $\min . \mathrm{A}$ & 400 \\
\hline $\min . \mathrm{B}$ & 396 \\
\hline $\min . \mathrm{C}$ & 1,500 \\
\hline $\min . \mathrm{D}$ & 453 \\
\hline
\end{tabular}

Table 4. Processing costs per unit.

\begin{tabular}{|c|c|c|c|}
\hline $5 \%$ cement & $10 \%$ cement & $25 \%$ cement & $90 \%$ cement \\
\hline $95 \%$ fly ash & $90 \%$ fly ash & $75 \%$ fly ash & $10 \%$ fly ash \\
\hline 25 Eur. $\mathrm{t}^{-1}$ & 28 Eur. $\mathrm{t}^{-1}$ & 37 Eur. $\mathrm{t}^{-1}$ & 74 Eur. $^{-1}$ \\
\hline
\end{tabular}

Since the chlorides of metals and non-metal in a higher oxidation state are fusible and volatile substances, they often decompose in water. In accordance with Decree No. 283/2001 of the Ministry of Environment of the Slovak Republic, the limit value for chloride is $1,500 \mathrm{mg} .1^{-1}$. The decree defines the limit values for individual heavy metals concentrations for each landfill type, which must not be exceeded.

\section{Conclusions}

The extreme objective function for chlorides is point $\mathrm{B}$, which is the intersection of lines 3 and 4 . The minimum value of chlorides is represented by two conditions, namely:

1. $25 \%$ ratio of cement and $75 \%$ ratio of fly ash.

2. $90 \%$ ratio of cement and $10 \%$ ratio of fly ash.

The resulting ratio for chloride is located in the recommended field, which also presents the values in Table 3. After calculating the relevant ratios by the price of cement (80 EUR. $\left.\mathrm{t}^{-1}\right)$ and the price of fly ash (22 EUR. $\left.\mathrm{t}^{-1}\right)$, the least favorable in terms of financial cost is the ratio of $90 \%$ cement and $10 \%$ fly ash (Table 4 ).

Considering the aspect of binding chemicals during the process of stabilization, the most significant hurdle is represented by chlorides, which shows enhanced values. The main causes for the elevated values are salts, which are added to the recipe, and which make it more difficult to reduce chlorides. Fig. 2 shows that the limit of chlorides was exceeded only in certain cases.

To find the optimal ratio of fly ash and cement it is necessary to take into account the financial costs. The optimum ratio of $75 \%$ fly ash and $25 \%$ cement was found on the basis of performed interpolation and of graphical linear optimization. This ratio should also ensure that the chlorides, which for treatment of fly ash are the biggest problem, are below legal limits using this ratio. Chlorides are in fact resistant to solidification and also confirm the finding that the formula for solidification of fly ash contains salts [7]. Results of graphical solutions of the linear optimization show that other chemicals used for fly ash stabilization are far below the specified legislative limits and do not pose a problem.

\section{Acknowledgements}

This work was supported by the Slovak Research and Development Agency under VEGA grants Nos. 1/0216/13 and No. 1/0552/14.

\section{References}

1. MALINDZAKOVA M., STRAKA M., ROSOVA A., TREBUNA P. Modeling the process for incineration of municipal waste. Przemysl Chemiczny. 94 (8), 1260, 2015. 
2. SZABO S., FERENCZ V., PUCIHAR A. Trust, innovation and prosperity. Quality Innovation Prosperity. 17 (2), 1, 2013.

3. PACANA A., BEDNAROVA L., PACANA J., LIBERKO I., WOZNY A., MALINDZAK D. Effect of selected factors of the production process of stretch film for its resistance tu puncture. Przemysl Chemiczny. 93 (12), 1, 2014.

4. SANIUK S., SANIUK A. Rapid prototyping of constraintbased production flows in outsourcing. Advanced Materials Research. 44-46 (1), 355, 2008.
5. BESTA P., SAMOLEJOVA A., JANOVSKA K., LAMPA M., LENORT R. Evaluation of benefits resulting from innovation of input raw materials dosing process in sintering. Metalurgija. 51 (4), 457, 2012.

6. PEKARCIKOVA M., TREBUNA P., MARKOVIC J. Simulation as part of industrial practice. Acta Logistica. 2 (2), 5, 2015.

7. STRAKA M., ZATKOVIC E., SCHRETER R. Simulation as a means of activity streamlining of continuously and discrete production in specific enterprise. Acta Logistica. 1 (3), 11, 2014. 